OPEN ACCESS

Edited by:

Zhicheng Zhang,

Tianjin University, China

Reviewed by:

Sangaraju Shanmugam, Daegu Gyeongbuk Institute of Science and Technology (DGIST), South Korea

Yunwen Wu,

Shanghai Jiao Tong University, China

*Correspondence:

Ning Wang

wangning5637@163.com

Jian Zhang

zhangjian7@hust.edu.cn

Specialty section:

This article was submitted to

Electrochemical Energy

Conversion and Storage,

a section of the journal

Frontiers in Energy Research

Received: 03 September 2020

Accepted: 12 October 2020

Published: 04 December 2020

Citation:

Wang N, Song Q-S, LiU W-J and Zhang $J$ (2020) The Synthesis of $\mathrm{V}_{2} \mathrm{O}_{3}$ Nanorings by Hydrothermal Process as an Efficient Electrocatalyst Toward

$\mathrm{N}_{2}$ Fixation to $\mathrm{NH}_{3}$.

Front. Energy Res. 8:602438.

doi: 10.3389/fenrg.2020.602438

\section{The Synthesis of $\mathrm{V}_{2} \mathrm{O}_{3}$ Nanorings by Hydrothermal Process as an Efficient Electrocatalyst Toward $\mathrm{N}_{2}$ Fixation to $\mathrm{NH}_{3}$}

\author{
Ning Wang ${ }^{1 *}$, Qing-Song Song ${ }^{1}$, Wen-Jing Liu ${ }^{1}$ and Jian Zhang ${ }^{2 *}$ \\ ${ }^{1}$ Key Laboratory of Flexible Electronics (KLOFE) and Institute of Advanced Materials (IAM), Jiangsu National Synergistic Innovation \\ Center for Advanced Materials (SICAM), Nanjing Tech University (Nanjing Tech), Nanjing, China, ${ }^{2}$ Key Laboratory of Material \\ Chemistry for Energy Conversion and Storage, Ministry of Education, School of Chemistry and Chemical Engineering, Huazhong \\ University of Science and Technology, Wuhan, China
}

A new ringlike $\mathrm{V}_{2} \mathrm{O}_{3}$ architecture was successfully synthesized by a template-free hydrothermal method, and the sulfur ions-assisted central-etching mechanism of the ringlike structure was proposed. Herein, as a proof-of-concept experiment, taking $\mathrm{V}_{2} \mathrm{O}_{3}$ nanorings as non-noble-metal-free nitrogen reduction reaction (NRR) catalysts, they show desired electrocatalytic performance toward NRR under ambient conditions (maximum yield: $47.2 \mathrm{\mu g} \mathrm{h}^{-1} \mathrm{mg}_{\mathrm{cat}}{ }^{-1}$ at $-0.6 \mathrm{~V}$ vs. reversible hydrogen electrode, maximum Faraday efficiency: $12.5 \%$ at $-0.5 \mathrm{~V}$ vs. reversible hydrogen electrode), which is significantly higher than those of noble metal-based catalysts.

Keywords: nanorings, vanadium oxides, hydrothermal method, $\mathrm{N}_{2}$ fixation, electrocatalyst

\section{INTRODUCTION}

The precise nanofabrication is of great significance in both fundamental research and practical applications. The past few decades have witnessed a remarkable progress in the synthesis of zero-, one-, and two-dimensional nanomaterials (Chiu et al., 2011; Cao et al., 2020; Wang et al., 2020), which have aroused widespread interest due to the fascinating size/figure-dependent properties. During a variety of nanostructures, ringlike architectures exhibit novel properties with ring cavities and present promising application prospects in catalysis, sensors, energy storage, and advanced optical/electric nanodevices (Chen et al., 2017). Various strategies have been developed to fabricate ring architectures, including electron beam lithography (EBL), gas bubbles-assisted method (Wang et al., 2018), microwave-induced nucleation-aggregation-dissolution method (Hu et al., 2007), ultrasonic irradiation method (Miao et al., 2006), self-assembly method (Zhai et al., 2010), or epitaxial self-coiling method. Yet, most synthetic strategies are expensive or complicated. Thus, it is still a demanding problem to develop scalable liquid phase synthesis techniques for fabricating cyclic annular architecture in various forms with functionality.

The conversion of atmospheric nitrogen $\left(\mathrm{N}_{2}\right)$ into ammonia $\left(\mathrm{NH}_{3}\right)$ is an important process for both mankind and biologic system of the planet (Li et al., 2017; Ma et al., 2017). It is predicted that almost half of the world's people would suffer from hunger, if there are no amino-group inorganic fertilizers (Bao et al., 2017; Xue et al., 2019). However, it is significant challenge to convert $\mathrm{N}_{2}$ to $\mathrm{NH}_{3}$, because of the extremely high bond strength of $941 \mathrm{~kJ} \times \mathrm{mol}^{-1}$ and the absence of a dipole moment (Bao et al., 2017; Cao et al., 2018). Thus, it is of indispensable significance to develop $\mathrm{N}_{2}$ fixation technologies that can satisfy the current needs of the fertilizer industry (Montoya et al., 2015; Cao 
et al., 2018). The traditional Haber-Bosch process needs severe reaction conditions $\left(200-250 \mathrm{bar}, 400-500^{\circ} \mathrm{C}\right)$ to produce $\mathrm{NH}_{3}$ using $\mathrm{N}_{2}$ and hydrogen $\left(\mathrm{H}_{2}\right)$ as feed gases (Qiu et al., 2018; Wu et al., 2018; Zhang L. et al., 2018), while it supplies a comparably inferior equilibrium conversion yield of ca. $15 \%$ and inevitable $\mathrm{CO}_{2}$ emissions (1.5 tons $\mathrm{CO}_{2}$ for one ton $\mathrm{NH}_{3}$ produced) (Bao et al., 2017; Cao et al., 2018; Chirik, 2009; Ham et al., 2014). Although biological $\mathrm{N}_{2}$ fixation can be able to boost the formation of ammonia in the moist air at temperate reaction conditions, the impressive energy efficiency could scarcely meet the demand of global need (Broda et al., 2014; Seh et al., 2017). Encouragingly, electrochemical $\mathrm{N}_{2}$ fixation proceeds $\left(\mathrm{N}_{2}+6 \mathrm{H}^{+}+6 \mathrm{e}^{-} \rightarrow 2 \mathrm{NH}_{3}\right)$ under milder conditions and can be powered by electricity from sustainable sources, which provides a new environmentally friendly process for sustainable synthesis of $\mathrm{NH}_{3}$ under normal temperature and pressure (Shipman et al., 2017; Yang et al., 2020).

Usually, NRR catalysts based on metal-based catalysts, specifically noble metal-based ones, like Au (Shi et al., 2018), Pd (Wang et al., 2018), and Ru (Zhang Y. et al., 2018), show satisfactory activity, yet extensive use is hindered by the less abundance and huge expenses. Thus, a lot of attention has been focused on the design and development of non-noble-metal substitutes, including metal oxides (Liu et al., 2018), transition metal disulfide (Zhang L. et al., 2018), carbides (Cheng et al., 2018; Qiu et al., 2018), and nitrides (Yang et al., 2018; Zhang X. P. et al., 2018). However, non-noble-metal electrocatalysts always suffer from low Faradaic efficiency (FE). Vanadium oxides, a kind of inorganic functional material, have been widely studied for energy storage and conversion, including supercapacitors, aqueous lithium ion batteries, and thermoelectric generators (Wu et al., 2013; Zeng et al., 2016; Liu et al., 2017; Shao et al., 2019), due to their abundance in natural resources and low production cost. To date, their electrochemical uses as NRR catalysts is still scarcely explored up to now.

Herein, we report the versatile synthesis of $\mathrm{V}_{2} \mathrm{O}_{3}$ nanorings via a scalable hydrothermal method. The formation mechanism has been studied in detail. As a proof-of-concept experiment, we show that the ringlike $\mathrm{V}_{2} \mathrm{O}_{3}$ nanostructure serves as a superb catalyst for $\mathrm{N}_{2}$ fixation at room temperature with excellent selectivity to synthesized $\mathrm{NH}_{3}$ product. As-prepared nanostructure, in $0.1 \mathrm{M} \mathrm{Na}_{2} \mathrm{SO}_{4}$, enables electrocatalytic NRR with a desired $\mathrm{FE}$ of $12.5 \%$ at $-0.5 \mathrm{~V}$ versus reversible hydrogen electrode (RHE).

\section{MATERIALS AND METHODS}

\section{Chemicals}

Salicylic acid $\left(\mathrm{C}_{7} \mathrm{H}_{6} \mathrm{O}_{3}\right)$, sodium nitroferricyanide dihydrate $\left(\mathrm{C}_{5} \mathrm{FeN}_{6} \mathrm{Na}_{2} \mathrm{O} \cdot 2 \mathrm{H}_{2} \mathrm{O}\right), \quad p$-dimethylaminobenzaldehyde $\left(\mathrm{C}_{9} \mathrm{H}_{11} \mathrm{NO}\right)$, ammonium chloride $\left(\mathrm{NH}_{4} \mathrm{Cl}\right)$, sodium hydroxide $(\mathrm{NaOH})$, sodium sulfate $\left(\mathrm{Na}_{2} \mathrm{SO}_{4}\right)$, sodium citrate dehydrate $\left(\mathrm{C}_{6} \mathrm{H}_{5} \mathrm{Na}_{3} \mathrm{O}_{7} .2 \mathrm{H}_{2} \mathrm{O}\right)$, and thioacetamide $\left(\mathrm{CH}_{3} \mathrm{CSNH}_{2}\right)$ were purchased from Sigma-Aldrich (Steinheim, Germany). 15Ammonium sulfate $\left[\left({ }^{15} \mathrm{NH}_{4}\right)_{2} \mathrm{SO}_{4}\right]$ was purchased from Aladdin Chemical Reagent Co., Ltd (Shanghai, China).
Hydrochloric acid $(\mathrm{HCl})$ and sodium orthovanadate $\left(\mathrm{Na}_{3} \mathrm{VO}_{4}\right)$ were purchased from Sinopharm Chemical Reagent Co., Ltd (Shanghai, China). Sodium hypochlorite solution $(\mathrm{NaClO})$ and ethanol $\left(\mathrm{C}_{2} \mathrm{H}_{5} \mathrm{OH}\right)$ were purchased from TCI Development Co., Ltd (Shanghai, China). All reagents were used as received without further purification.

\section{Synthesis of $\mathrm{V}_{\mathbf{2}} \mathrm{O}_{3}$ Nanorings}

Sodium orthovanadate $(0.125 \mathrm{~g})$ and thioacetamide $(0.1125 \mathrm{~g})$ were dissolved in $100 \mathrm{ml}$ distilled water in a $150 \mathrm{ml}$ Teflon-lined stainless-steel autoclave, which was sealed and heated to $200^{\circ} \mathrm{C}$ $\left(160^{\circ} \mathrm{C}, 180^{\circ} \mathrm{C}\right)$ at $5^{\circ} \mathrm{C} \mathrm{min}^{-1}$ and hold at constant temperature for stated time $(0-24 \mathrm{~h})$ and then cooled naturally to room temperature with furnace. Finally, the product is collected by centrifugation and washed with deionized water in turn before further characterizations.

\section{Characterizations}

The morphological, structural, and compositional characterizations of the products were investigated by scanning electron microscopy (SEM, Hitachi S-4800, Japan), high-resolution transmission electron microscope (HRTEM, JEOL 2100F, Japan) coupled with energy dispersive X-ray (EDX) spectroscopy, UV-Vis spectrophotometer (Shimadzu 2600, Japan), X-ray diffraction (XRD, SmartLab Rigaku, Japan), and X-ray photoelectron spectroscopy (XPS, Thermo ESCALAB 250Xi, USA). The XRD characterization was carried out on a diffractometer equipped with $\mathrm{Cu} \mathrm{Ka}$ radiation $(\lambda=$ $1.54 \AA$ ). For the XPS measurements, the binding energies were corrected for specimen charging effects using the $\mathrm{C} 1 \mathrm{~s}$ level at $284.6 \mathrm{eV}$ as the reference. A JEOL JNM-ECZ400S/L1 spectrometer was used to record proton nuclear magnetic resonance $(400 \mathrm{MHz})$, and dimethyl sulfoxide (DMSO) was used as a solvent.

\section{Electrochemical Measurements}

Before NRR test, Nafion 211 membrane was treated by first heating it in $\mathrm{H}_{2} \mathrm{O}_{2}(5 \mathrm{wt} \%)$ aqueous solution for $1 \mathrm{~h}$, then in deionized water for $1 \mathrm{~h}$, followed by $1 \mathrm{~h}$ in $0.5 \mathrm{M} \mathrm{H}_{2} \mathrm{SO}_{4}$, and ultimately for $1 \mathrm{~h}$ in ultrapure water (Ketpang et al., 2015). Above steps were all carried out at $80^{\circ} \mathrm{C}$. A VMP3 electrochemical workstation (Bio-Logic, Claix, France) was used to carry out electrochemical measurements in a twocompartment cell separated by Nafion 211 membrane. A standard three-electrode system used a saturated $\mathrm{Ag} / \mathrm{AgCl}$ as the reference electrode and a Pt electrode as counter electrode, respectively. The working electrode was prepared by successively drop-casting samples and Nafion solutions (0.01 wt\%) onto the carbon paper (CP). The loading amount of all the catalysts was $0.02 \mathrm{mg}$ on the working electrode. For $\mathrm{N}_{2}$ fixation test, the electrolyte was purged with ultrapure $\mathrm{N}_{2}$ for $0.5 \mathrm{~h}$ before every experiment. Chronoamperometric tests were carried out in $\mathrm{N}_{2}$ saturated $0.1 \mathrm{M} \mathrm{Na}_{2} \mathrm{SO}_{4}$. According to the following equation, all of the potentials were transformed to the RHE scale,

$$
\mathrm{E}_{\mathrm{RHE}}=\mathrm{E}_{\mathrm{Ag} / \mathrm{AgCl}}+0.1989+0.059 \cdot \mathrm{pH}
$$



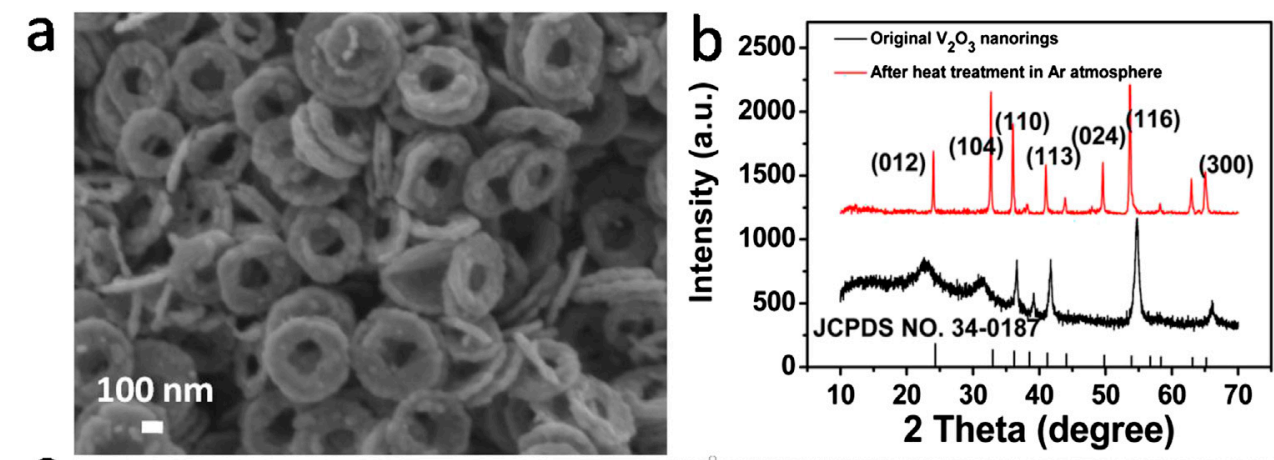

C
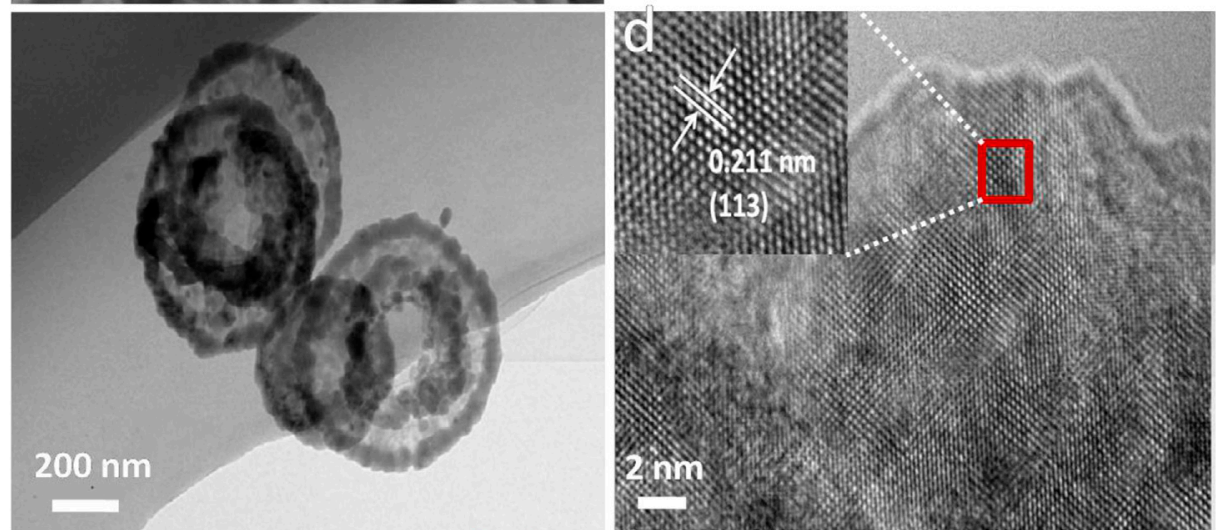

e

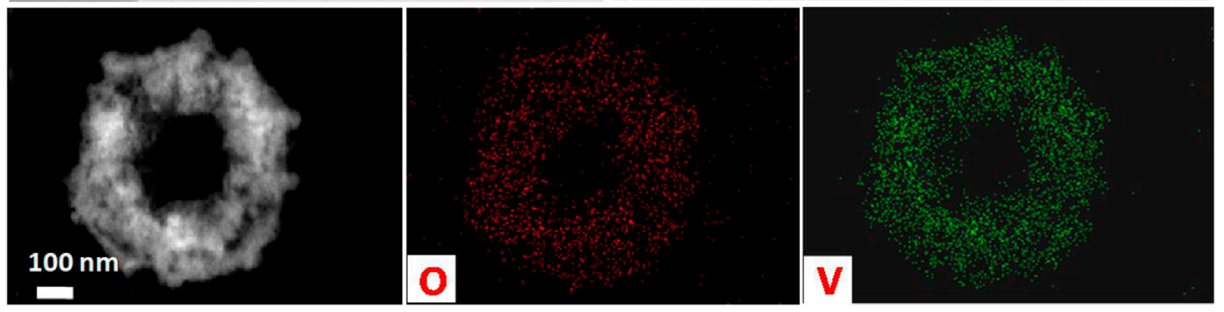

FIGURE 1 | (A) SEM image of the original $\mathrm{V}_{2} \mathrm{O}_{3}$ nanorings. (B) XRD pattern of the original $\mathrm{V}_{2} \mathrm{O}_{3}$ nanorings and the corresponding one after heat treatment in Ar atmosphere. (C) TEM and (D) HRTEM images of the original $\mathrm{V}_{2} \mathrm{O}_{3}$ nanorings. (E) STEM image of the original $\mathrm{V}_{2} \mathrm{O}_{3}$ nanoring and EDX elemental mapping of $\mathrm{V}$ and $\mathrm{O}$.
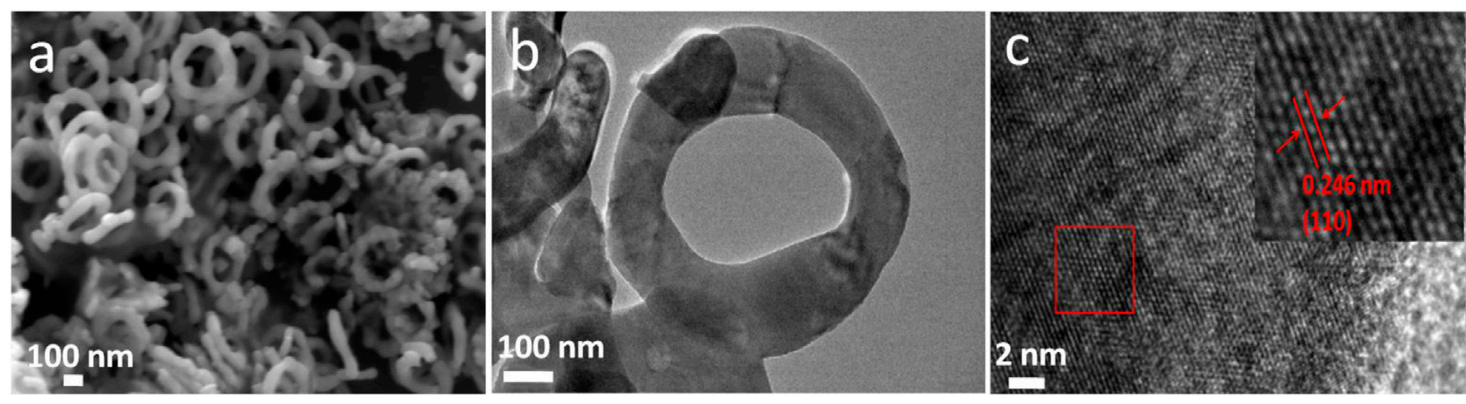

FIGURE 2 | (A,B) The SEM and TEM images of the nanorings after heat treatment in flow Ar atmosphere. (C) The corresponding HRTEM images of the nanoring showing an interplanar distance of $0.246 \mathrm{~nm}$ relative to the (110) Plane, which is consistent with the $\mathrm{V}_{2} \mathrm{O}_{3}$ crystal (JCPDS card No. $34-0187$ ).

\section{RESULTS AND DISCUSSION}

Scanning electron microscopy (SEM) analysis reveals the ringlike structure is uniform with outer diameter in the range of
$350-500 \mathrm{~nm}$, as shown in Figure 1A. Figure 1C exhibits a typical transmission electron microscopy (TEM) picture of a representative sample at lower magnification. It confirms that such nanoring has a rough surface. After heat treatment, the 


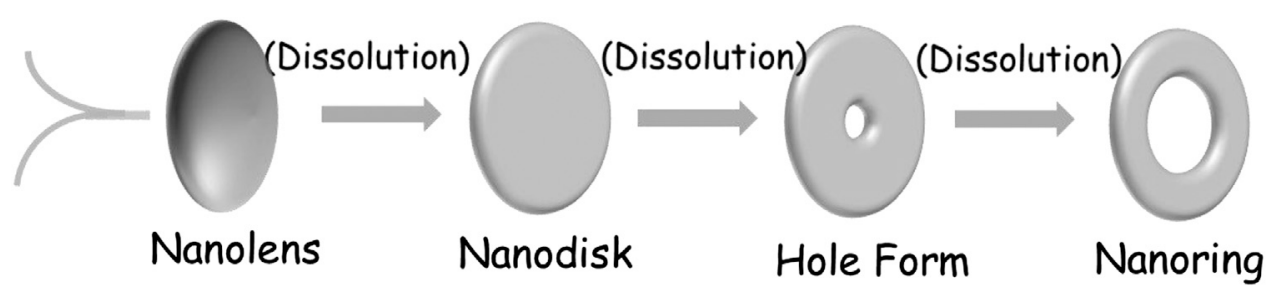

FIGURE 3 | Schematic illustration of $\mathrm{V}_{2} \mathrm{O}_{3}$ nanoring formation.

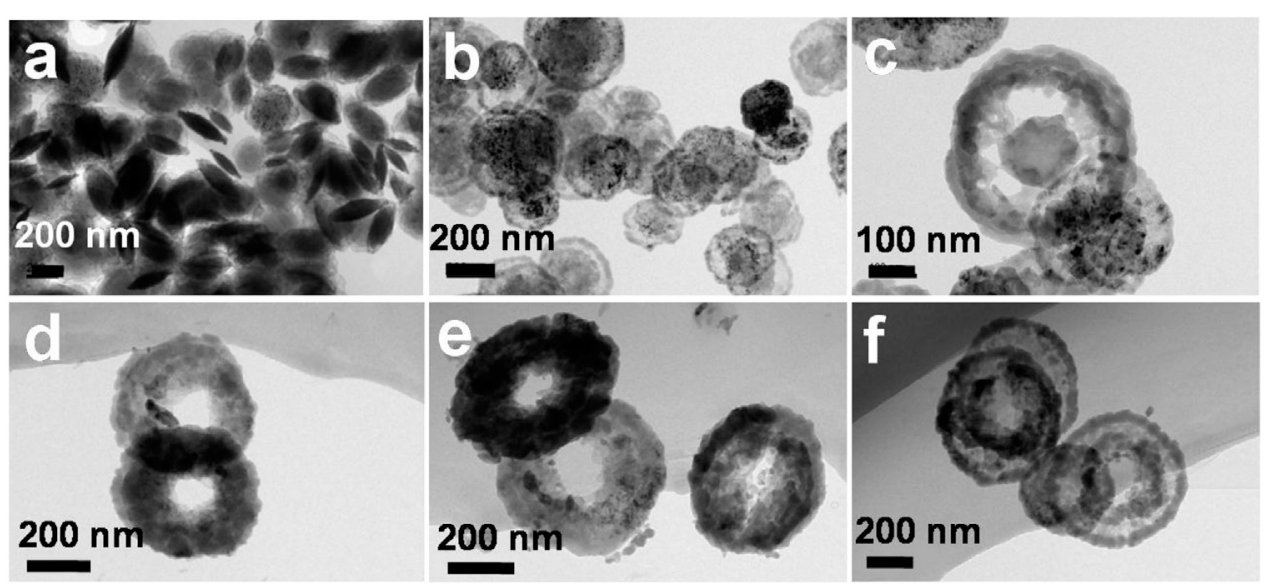

FIGURE 4 | The formation process of the $\mathrm{V}_{2} \mathrm{O}_{3}$ nanorings, (A) $<2 \mathrm{~h}$, (B) $2 \mathrm{~h}$, (C) $3 \mathrm{~h}$, (D) $4 \mathrm{~h}$, (E) $6 \mathrm{~h},(\mathbf{F}) 8 \mathrm{~h}$.

surface of nanorings become smooth (Figure 2). The $\mathrm{X}$-ray diffraction (XRD) patterns are showed in Figure 1B for the $\mathrm{V}_{2} \mathrm{O}_{3}$ nanoring powder before and after heat treatment. The XRD data of the original $\mathrm{V}_{2} \mathrm{O}_{3}$ nanorings show the shift in the peak position due to the lattice distortion of ringlike structure, as well as the broadening of the peaks, indicating the existence of microstrain (JCPDS card No. 34-0187) (Chattot et al., 2018). Note that microstrain has broadened the peaks and never changed the peak position, because the atoms deviated from the desired positions when structure defects exist, like stacking faults and grain boundaries (Li et al., 2004). The highresolution TEM (HRTEM) (Figure 1D) picture of one single nanoring demonstrates a contracted interplanar distance of $0.211 \mathrm{~nm}$ corresponding to the (113) Plane, which well conforms to the XRD data. X-ray photoelectron spectroscopy (XPS) (Supplementary Figure S1) further demonstrates the formation of $\mathrm{V}_{2} \mathrm{O}_{3}$. For the $\mathrm{V} 2 \mathrm{p}$ spectrum, two distinct peaks at binding energies of $\sim 516.0 \mathrm{eV}$ for $\mathrm{V} 2 \mathrm{p} 3 / 2$ and $\sim 524.0 \mathrm{eV}$ for $\mathrm{V} 2 \mathrm{p} 1 / 2$ are observed. It is characteristic of vanadium in the +3 oxidation state, indicating the preparation of $\mathrm{V}_{2} \mathrm{O}_{3}$ (Jiang et al., 2015). After heat treatment in flow Ar atmosphere, the peak position becomes consistent with that of the $\mathrm{V}_{2} \mathrm{O}_{3}$ crystal due to the release of stress (JCPDS card No. 34-0187, Figures 1B, 2C). The corresponding STEM and EDX mapping pictures indicate the uniformly distributed $\mathrm{V}$ and $\mathrm{O}$ elements for $\mathrm{V}_{2} \mathrm{O}_{3}$ nanorings before and after heat treatment (Figure 1E; Supplementary Figure S2).

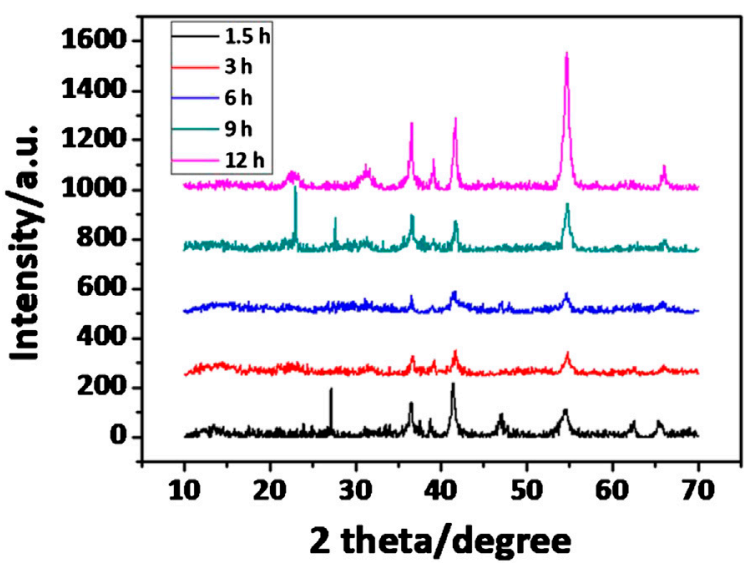

FIGURE 5 | The XRD patterns of the nanorings at varying reaction time (0-12 h).

In this work, $\mathrm{V}_{2} \mathrm{O}_{3}$ nanoring is obtained by one-dot hydrothermal method without template assistance. Concerning the formation mechanism, the included $S^{2-}$ derived from the decomposition of thioacetamide (TAA) must have played the key roles during the "etching" of the nanodisk, because surfactants/ templates/emulsions are not contained inside during the reaction. At this point, we put forward a central-etching process for the 
formation of $\mathrm{V}_{2} \mathrm{O}_{3}$ nanorings, as schematically depicted in Figure 3. The shape evolution of as-prepared $\mathrm{V}_{2} \mathrm{O}_{3}$ nanoring was studied by varying the hydrothermal reaction time (Figure 4; Supplementary Figure S3). At the beginning of the synthesis process $(<2 \mathrm{~h})$, nanolens with thicker center and diameter of 300-500 nm were observed. With the extended reaction time, the inner part of the nanolens became thinner to form holes under etching $(<4 \mathrm{~h})$. After the reaction had proceeded for over $4 \mathrm{~h}$, nanorings with outer diameter of $300-500 \mathrm{~nm}$ form and keep stable even at longer time. XRD patterns (Figure 5) at different reaction time revealed the lattice distortion and microstrain exist throughout the process.

TAA can be hydrolyzed into sulfide ions in alkaline environment (Eq. 2). Then the included sulfide ions will be more inclined to "etch" the raised center of $\mathrm{V}_{2} \mathrm{O}_{3}$ nanodisk, thus resulting in more defects in the center of the nanodisk. Interestingly, the "etching effect" only happened in the inner part of the disks throughout the formation of ringlike structure. And the etching process is uniform from one disk to another, even to an individual disk (Figure 1A; Supplementary Figure S3).

$$
\mathrm{CH}_{3} \mathrm{CSNH}_{2}+3 \mathrm{OH}^{-} \Leftrightarrow \mathrm{CH}_{3} \mathrm{COO}^{-}+\mathrm{NH}_{3}+\mathrm{S}^{2-}+\mathrm{H}_{2} \mathrm{O}
$$

To understand the control mechanism of the $\mathrm{V}_{2} \mathrm{O}_{3}$ nanorings, a series of experiments were designed to make clear the influence of the content of reagents on the growth of the $\mathrm{V}_{2} \mathrm{O}_{3}$ nanorings. In several experimental variables, TAA during the reaction plays a major role in the size control of $\mathrm{V}_{2} \mathrm{O}_{3}$ nanorings (Supplementary Figure S4). According to Eq. 2, the amount of TAA added dominates the amount of free sulfide ions which are responsible for the dissolution of nanodisks. When the amounts of TAA increased from 0.1125 to $0.50 \mathrm{~g}$ in $100 \mathrm{ml}$ deionized water, the outer diameter of the nanoring decreased from ca. $500 \mathrm{~nm}$ to ca. $200 \mathrm{~nm}$. Furthermore, when the amount of TAA increased to $1.250 \mathrm{~g}$, the inner diameter shrank and almost disappeared. Experimental results show that the morphology is sensitive to temperature in solution (Supplementary Figure S5). When the temperature is below $200^{\circ} \mathrm{C}$, flower-like architecture forms instead of nanoring.

Interestingly, the morphology of etching-induced nanorings shows distinct variation with the concentration of solution (Supplementary Figures S6 and S7). When the solution was diluted, the nanodisks were less etched, leaving several holes in the middle. On the contrary, the concentrated solution generated layer-by-layer stacked nanodisks with the center etched. Layerby-layer stacked architecture has been reported previously based on different mechanisms. For instance, anionic surfactant (PVP) serves as a bridging agent to hold neighboring disulfide nanosheets together due to electrostatic interactions (Sun et al., 2017). The formation of ultrathin CuS nanosheets can be explained by the micellar-templating mechanism (Du et al., 2012). In our work, no surfactant or micellar was used in the precursors. The formation mechanism of stacked architecture requires further investigation.

As a proof-of-concept demonstration, as-prepared nanorings serve as a catalyst for ambient $\mathrm{N}_{2}$ fixation. The NRR ability was evaluated in an H-typed electrolytic cell (Supplementary Figure
S8). $\mathrm{V}_{2} \mathrm{O}_{3}$ nanorings were uniformly dispersed on a carbon paper electrode $\left(\mathrm{V}_{2} \mathrm{O}_{3} / \mathrm{CPE}\right.$, loading: $\left.0.02 \mathrm{mg} / \mathrm{cm}^{2}\right)$, with $\mathrm{Ag} / \mathrm{AgCl}$ as reference electrode and $\mathrm{Pt}$ electrode as counter electrode, respectively. In advance of each NRR test, $\mathrm{N}_{2}$ is transported toward the working electrode surface in the electrolyte for $30 \mathrm{~min}$. Chronoamperometric tests were then conducted at constant $\mathrm{N}_{2}$ flow rate for $2 \mathrm{~h}$. All NRR catalytic performance tests were conducted in $0.1 \mathrm{M} \mathrm{Na}_{2} \mathrm{SO}_{4}$ electrolytes and the magnitude of current density varied with the applied potentials. In order to verify the reduced $\mathrm{NH}_{3}$ is generated via the electrocatalytic process, the linear sweep voltammetric (LSV) curve using $\mathrm{V}_{2} \mathrm{O}_{3} / \mathrm{CPE}$ as the working electrode is performed in $\mathrm{N}_{2^{-}}$ saturated (black line) and Ar-saturated (purple line) electrolytes, respectively (Supplementary Figure S10). The produced $\mathrm{NH}_{3}$ concentration was quantified using the calibration curves set up by the indophenol blue method (Zhu et al., 2013), and possible byproduct hydrazine $\left(\mathrm{N}_{2} \mathrm{H}_{4}\right)$ was detected using a spectrophotometric method researched by Watt and Chrisp (Ensafi et al., 1999).

Figure 6A demonstrates the chronoamperometry results at varied potentials of the $\mathrm{V}_{2} \mathrm{O}_{3}$ nanorings under $\mathrm{N}_{2}$ atmosphere. During the electrolytic tests, negligible decay in current density except the potential at $-0.9 \mathrm{~V}$ was observed for the $\mathrm{V}_{2} \mathrm{O}_{3} / \mathrm{CPE}$ catalyst, revealing the good durability of as-prepared catalyst within a certain potential range. Figure $6 \mathbf{B}$ demonstrates the $\mathrm{UV}$-Vis absorption spectra of electrolytes in a wide voltage range from -0.5 to $-0.9 \mathrm{~V}$ colored with the indophenol indicator. The highest absorbance intensity of the electrolyte appeared at the voltage of $-0.6 \mathrm{~V}$. The relationship between $\mathrm{NH}_{3}$ yields, Faradaic efficiencies (FEs), and applied potential is plotted in Figure 6C. A peak value of produced $\mathrm{NH}_{3}$ is $47.2 \mu \mathrm{g} \mathrm{h}^{-1} \mathrm{mg}_{\text {cat. }}{ }^{-1}$ at the potential of $-0.6 \mathrm{~V}$ versus RHE. Owing to the competitive hydrogen evolution reaction (HER) activity over $\mathrm{V}_{2} \mathrm{O}_{3} / \mathrm{CPE}$, the $\mathrm{NH}_{3}$ yield decreases distinctly after the peak voltage of $-0.6 \mathrm{~V}$, and the competition reaction between NRR and HER was previously elaborated in numerous researches. The best value of FE (12.5\%) was acquired at the optimal potential of $-0.50 \mathrm{~V}$ versus RHE. Comparing with most reported $\mathrm{N}_{2}$ fixation electrocatalysts under ambient conditions, the performance is preferable (Supplementary Table S1). A ${ }^{15} \mathrm{~N}$ isotopic labeling experiment using ${ }^{15} \mathrm{~N}_{2}$-enriched gas as the raw gas was also conducted to verify the exact $\mathrm{N}$ source of the synthesized $\mathrm{NH}_{3}$, as shown in Supplementary Figure S12. In the ${ }^{1} \mathrm{H}$ nuclear magnetic resonance $\left({ }^{1} \mathrm{H}\right.$ NMR) spectra, a doublet coupling for ${ }^{15} \mathrm{NH}_{4}{ }^{+}$appears in the reaction product. The results powerfully support that the exact $\mathrm{N}$ source in $\mathrm{NH}_{3}$ originates from the gaseous $\mathrm{N}_{2}$ provided. Moreover, hydrazine was not detected in our research within the detection limit of the spectrophotometric means, indicating the good selectivity of the catalyst (Supplementary Figures S11 and S13). Additionally, stability is another critical criterion to be evaluated for catalysts. Figure 6D shows the $\mathrm{NH}_{3}$ yield rate and FEs of $\mathrm{V}_{2} \mathrm{O}_{3} / \mathrm{CPE}$ at $-0.6 \mathrm{~V}$ versus RHE scarcely change during eight successive NRR tests, confirming its excellent durability (UV-Vis absorption spectra and chronoamperometry curves are shown in Supplementary Figure S14). 

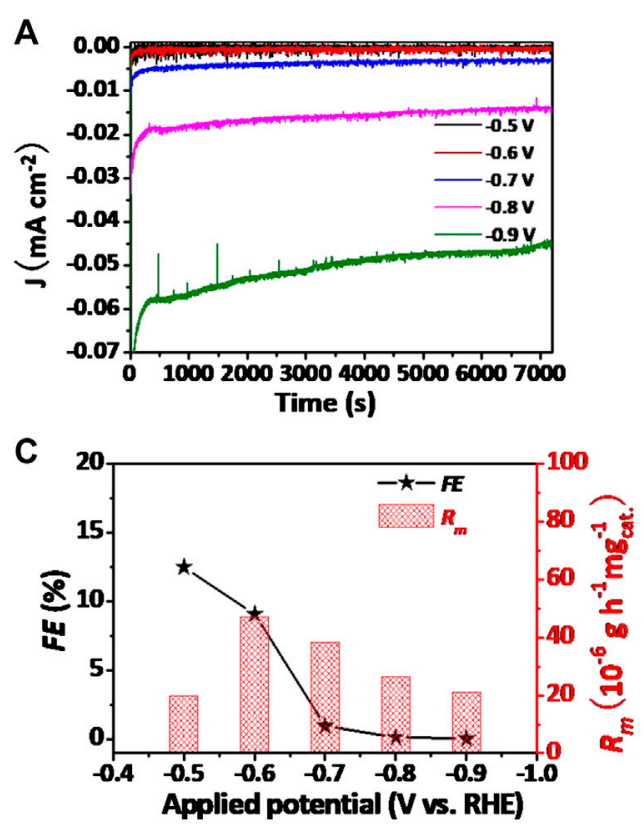
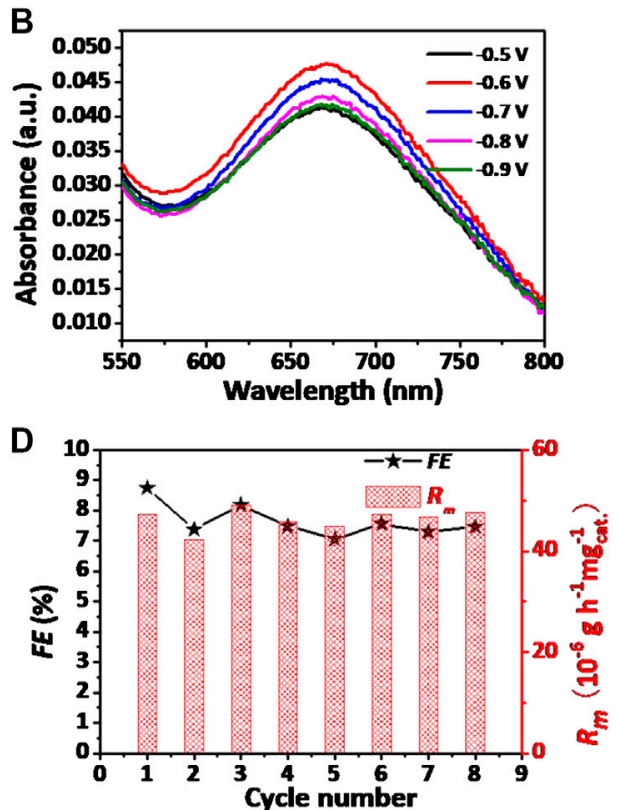

FIGURE 6 | (A) Chronoamperometry curves of $\mathrm{V}_{2} \mathrm{O}_{3} / \mathrm{CPE}$ at varied potentials. (B) UV-Vis absorption spectra of the solution mixed with indophenol indicator after electrochemical $\mathrm{N}_{2}$ fixation at a series of potentials for $2 \mathrm{~h}$. (C) Average $\mathrm{NH}_{3}$ yields and $\mathrm{FEs}$ of $\mathrm{V}_{2} \mathrm{O}_{3} / \mathrm{CPE}$ at different potentials. (D) Cycling test of $\mathrm{V}_{2} \mathrm{O}_{3} / \mathrm{CPE}$ during $\mathrm{N}_{2}$ fixation at $-0.6 \mathrm{~V}$.

\section{CONCLUSION}

In summary, $\mathrm{V}_{2} \mathrm{O}_{3}$ nanorings with controlled size and morphology have been successfully synthesized by one-dot hydrothermal method. The as-formed architecture brings new blood into the family of vanadium oxide nanostructures, which is confirmed to be a splendid catalyzer for electrochemical $\mathrm{N}_{2}$ conversion to $\mathrm{NH}_{3}$ at ambient temperature. At $-0.5 \mathrm{~V}$ versus RHE, this catalyst achieves a higher FE of $12.5 \%$ in neutral media, exhibiting strong long-term durability of electrochemical $\mathrm{N}_{2}$ fixation. Our research not only offers us a desirable nonnoble-metal electrocatalyst for electrochemical $\mathrm{N}_{2}$ fixation, but also develops a stirring new direction to explore the use of $\mathrm{V}$-based catalysts for $\mathrm{NH}_{3}$ synthesis.

\section{DATA AVAILABILITY STATEMENT}

The original contributions presented in the study are included in the article/Supplementary Material; further inquiries can be directed to the corresponding authors.

\section{REFERENCES}

Bao, D., Zhang, Q., Meng, F. L., Zhong, H. X., Shi, M. M., Zhang, Y., et al. (2017). Electrochemical reduction of $\mathrm{N}_{2}$ under ambient conditions for artificial $\mathrm{N}_{2}$ fixation and renewable energy storage using $\mathrm{N}_{2} / \mathrm{NH}_{3}$ cycle. Adv. Mater. 29, 1604799. doi:10.1002/adma.201604799

\section{AUTHOR CONTRIBUTIONS}

NW contributed to the synthesis, characterization, and manuscript writing. Q-SS and W-JL contributed to the synthesis and discussion of obtained results. JZ contributed to the performance test and manuscript writing. All authors contributed to the article and approved the submitted version.

\section{ACKNOWLEDGMENTS}

The authors would like to acknowledge financial support from the National Natural Science Foundation of China (No. 21706128) and China Postdoctoral Science Foundation (No. 2017M611794).

\section{SUPPLEMENTARY MATERIAL}

The Supplementary Material for this article can be found online at: https://www.frontiersin.org/articles/10.3389/fenrg.2020.602438/ full\#supplementary-material

Broda, H., and Tuczek, F. (2014). Catalytic ammonia synthesis in homogeneous solution-biomimetic at last? Angew. Chem. Int. Ed. 53, 632. doi:10.1002/anie. 201308780

Cao, N., and Zheng, G. (2018). Aqueous electrocatalytic $\mathrm{N}_{2}$ reduction under ambient conditions. Nano Res. 11, 2992. doi:10.1007/s12274-018-1987-y

Cao, X. Q., Zhou, J., Li, S., and Qin, G. W. (2020). Ultra-stable metal nano-catalyst synthesis strategy: a perspective. Rare Met. 39, 113. doi:10.1007/s12598-019-01350-y 
Chattot, R., Le, . O., Beermann, V., Kuhl, S. Herranz, J., Henning, S., et al. (2018). Surface distortion as a unifying concept and descriptor in oxygen reduction reaction electrocatalysis. Nat. Mater. 17, 827. doi:10.1038/s41563-018-0133-2

Chen, C. H., Wang, H. Y., Han, C. L., Deng, J., Wang, J., Li, M. M., et al. (2017). Asymmetric flasklike hollow carbonaceous nanoparticles fabricated by the synergistic interaction between soft template and biomass. J. Am. Chem. Soc. 139, 4625. doi:10.1021/jacs.6b10841

Cheng, H., Ding, L. X., Chen, G. F., Zhang, L. L., Xue, J., and Wang, H. H. (2018). Molybdenum carbide nanodots enable efficient electrocatalytic nitrogen fixation under ambient conditions. Adv. Mater. 30, 1803694. doi:10.1002/adma.201803694

Chirik, P. J. (2009). One electron at a time. Nat. Chem. 1, 520. doi:10.1038/ nchem.386

Chiu, C. Y., Li, Y. J., Ruan, L. Y., Ye, X. C., Murray, C. B., and Huang, Y. (2011). Platinum nanocrystals selectively shaped using facet-specific peptide sequences. Nat. Chem. 3, 393. doi:10.1038/nchem.1025

Du, Y., Yin, Z., Zhu, J., Huang, X., Wu, X. J., Zeng, Z., et al. (2012). A general method for the large-scale synthesis of uniform ultrathin metal sulphide nanocrystals. Nat. Commun. 3, 1177. doi:10.1038/ncomms2181

Ensafi, A. A., Sadeghie, M. M., and Emamei, F. (1999). Kinetic reaction rate method for the determination of hydrazine with spectrophotometric detection. J. Anal. Chem. 54, 1024. doi:10.2478/s11532-010-0021-3

Ham, C. J. M., Koper, M. T. M., and Hetterscheid, D. G. H. (2014). Challenges in reduction of dinitrogen by proton and electron transfer. Chem. Soc. Rev. 43, 5183. doi: $10.1039 / \mathrm{c} 4 \mathrm{cs} 00085 \mathrm{~d}$

$\mathrm{Hu}, \mathrm{X}$., Yu, J. C., Gong, J., Li, Q., and Li, G. (2007). $\alpha-\mathrm{Fe}_{2} \mathrm{O}_{3}$ nanorings prepared by a microwave-assisted hydrothermal process and their sensing properties. Adv. Mater. 19, 2324. doi:10.1002/adma.200602176

Jiang, L., Qu, Y., Ren, Z. Y., Yu, P., Zhao, D. D., Zhou, W., et al. (2015). In Situ carbon-coated yolk-shell $\mathrm{V}_{2} \mathrm{O}_{3}$ microspheres for lithium-ion batteries. ACS Appl. Mater. Interfaces 7, 1959. doi:10.1021/am5070393

Ketpang, K., Shanmugam, S., Suwanboon, C., Chanunpanich, N., and Lee, D. (2015). Efficient water management of composite membranes operated in polymer electrolyte membrane fuel cells under low relative humidity. J. Membr. Sci. 493, 285. doi:10.1016/j.memsci.2015.06.055

Li, G. S., Boerio-Goates, J., Woodfield, B. F., and Li, L. P. (2004). Evidence of linear lattice expansion and covalency enhancement in rutile $\mathrm{TiO}_{2}$ nanocrystals. Appl. Phys. Lett. 85, 2059. doi:10.1063/1.1790596

Li, S. J., Bao, D., Shi, M. M., Wulan, B., Yan, J. M., and Jiang, Q. (2017). Amorphizing of $\mathrm{Au}$ nanoparticles by $\mathrm{CeOx}-\mathrm{RGO}$ hybrid support towards highly efficient electrocatalyst for $\mathrm{N}_{2}$ reduction under ambient conditions. $A d v$. Mater. 29, 1700001. doi:10.1002/adma.201700001

Liu, P. C., Zhu, K. J., Gao, Y. F., Luo, H. J., and Lu, L. (2017). Recent progress in the applications of vanadium-based oxides on energy storage: from low-dimensional nanomaterials synthesis to 3D micro/nano-structures and free-standing electrodes fabrication. Adv. Energy Mater. 7, 1700547. doi:10.1002/aenm.201700547

Liu, Q., Zhang, X., Zhang, B., Luo, Y., Cui, G., Xie, F., et al. (2018). Ambient $\mathrm{N}_{2}$ fixation to $\mathrm{NH}_{3}$ electrocatalyzed by a spinel $\mathrm{Fe}_{3} \mathrm{O}_{4}$ nanorod. Nanoscale 10, 14386. doi:10.1039/c8nr04524k

Ma, J. L., Bao, D., Shi, M. M., Yan, J. M., and Zhang, X. B. (2017). Reversible nitrogen fixation based on a rechargeable lithium-nitrogen battery for energy storage. Inside Chem. 2, 525. doi:10.1016/j.chempr.2017.03.016

Miao, J. J., Fu, R. L., Zhu, J. M., Xu, K., Zhu, J. J., and Chen, H. Y. (2006). Fabrication of $\mathrm{Cd}(\mathrm{OH})(2)$ nanorings by ultrasonic chiselling on $\mathrm{Cd}(\mathrm{OH})(2)$ nanoplates. Chem. Commun. 3013. doi:10.1039/b604688f

Montoya, J. H., Tsai, C., Vojvodic, A., and Norskov, J. K. (2015). The challenge of electrochemical ammonia synthesis: a new perspective on the role of nitrogen scaling relations. ChemSusChem 8, 2180. doi:10.1002/cssc.201500322

Qiu, W., Xie, X. Y., Qiu, J., Fang, W. H., Liang, R., Ren, X., et al. (2018). Highperformance artificial nitrogen fixation at ambient conditions using a metalfree electrocatalyst. Nat. Commun. 9, 3485. doi:10.1038/s41467-018-05758-5

Seh, Z. W., Kibsgaard, J., Dickens, C. F., Chorkendorff, I. B., Norskov, J. K., and Jaramillo, T. F. (2017). Combining theory and experiment in electrocatalysis: insights into materials design. Science 355, eaad4998. doi:10.1126/science.aad4998

Shao, X. Z., Wang, H. Y., Yuan, M. L., Yang, J., Zhan, W. C., Wang, L., et al. (2019). Thermal stability of Si-doped $\mathrm{V}_{2} \mathrm{O}_{5} / \mathrm{WO}_{3}-\mathrm{TiO}_{2}$ for selective catalytic reduction of $\mathrm{NOx}$ by $\mathrm{NH}_{3}$. Rare Met. 38, 292. doi:10.1007/s12598-018-1176-x

Shi, M. M., Bao, D., Li, S. J., Wulan, B. R., Yan, J. M., and Jiang, Q. (2018). Anchoring $\mathrm{PdCu}$ amorphous nanocluster on graphene for electrochemical reduction of $\mathrm{N}_{2}$ to $\mathrm{NH}_{3}$ under ambient conditions in aqueous solution. $A d v$. Energy Mater. 8, 1800124. doi:10.1002/aenm.201800124

Shipman, M. A., and Symes, M. D. (2017). Recent progress towards the electrosynthesis of ammonia from sustainable resources. Catal. Today 286, 57. doi:10.1016/j.cattod.2016.05.008

Sun, R. M., Wei, Q. L., Sheng, J. Z., Shi, C. W., An, Q. Y., Liu, S. J., et al. (2017). Novel layer-by-layer stacked $\mathrm{VS}_{2}$ nanosheets with intercalation pseudocapacitance for high-rate sodium ion charge storage. Nanomater. Energy 35, 396. doi:10.1016/j.nanoen.2017.03.036

Wang, J., Yu, L., Hu, L., Chen, G., Xin, H., and Feng, X. (2018). Ambient ammonia synthesis via palladium-catalyzed electrohydrogenation of dinitrogen at low overpotential. Nat. Commun. 9, 1759. doi:10.1038/s41467-018-04213-9

Wang, M., Cui, Z. X., Xue, Y. Q., and Zhang, R. (2018). Template-free synthesis and crystal transition of ring-like $\mathrm{VO}_{2}(\mathrm{M})$. Cryst. Growth Des. 18, 4220. doi:10. 1021/acs.cgd.8b00146

Wang, X., Zhuang, J., Peng, Q., and Li, Y. D. (2020). A general strategy for nanocrystal synthesis. Nature 437, 4759. doi:10.1038/nature03968

Wu, C. Z., Feng, F., and Xie, Y. (2013). Design of vanadium oxide structures with controllable electrical properties for energy applications. Chem. Soc. Rev. 42, 5157. doi:10.1039/c3cs35508j

Wu, X., Xia, L., Wang, Y., Lu, W., Liu, Q., Shi, X., et al. (2018). $\mathrm{Mn}_{3} \mathrm{O}_{4}$ nanocube: an efficient electrocatalyst toward artificial $\mathrm{N}_{2}$ fixation to $\mathrm{NH}_{3}$. Small 14, 1803111. doi:10.1002/smll.201803111

Xue, X. L., Chen, R. P., Yan, C. Z., Zhao, P. Y., Hu, Y., Zhang, W. J., et al. (2019). Review on photocatalytic and electrocatalytic artificial nitrogen fixation for ammonia synthesis at mild conditions: advances, challenges and perspectives. Nano Res. 12, 1229. doi:10.1007/s12274-018-2268-5

Yang, C., Zhu, Y., Liu, J., Qin, Y., Wang, H., Liu, H., et al. (2020). Defect engineering for electrochemical nitrogen reduction reaction to ammonia. Nanomater. Energy 77, 105126. doi:10.1016/j.nanoen.2020.105126

Yang, X., Nash, J., Anibal, J., Dunwel, M., Kattel, S., Stavitski, E., et al. (2018). Mechanistic insights into electrochemical nitrogen reduction reaction on vanadium nitride nanoparticles. J. Am. Chem. Soc. 140, 13387. doi:10.1021/jacs.8b08379

Zeng, L., Pan, A. Q., Liang, S. Q., Wang, J. B., and Cao, G. Z. (2016). Novel synthesis of $\mathrm{V}_{2} \mathrm{O}_{5}$ hollow microspheres for lithium ion batteries. Sci. China Mater. 59, 567. doi:10.1007/s40843-016-5046-1

Zhai, Y. M., Zhai, J. F., and Dong, S. J. (2010). Temperature-dependent synthesis of CoPt hollow nanoparticles: from "nanochain" to "nanoring". Chem. Commun. 46, 1500. doi:10.1039/b923466g

Zhang, L., Ji, X. Q., Ren, X., Ma, Y. J., Shi, X. F., Tian, Z. Q., et al. (2018). Electrochemical ammonia synthesis via nitrogen reduction reaction on a $\mathrm{MoS}_{2}$ catalyst: theoretical and experimental studies. Adv. Mater. 30, 1800191. doi:10. 1002/adma.201800191

Zhang, X. P., Kong, R. M., Du, H. T., Xia, L., and Qu, F. L. (2018). Highly efficient electrochemical ammonia synthesis via nitrogen reduction reactions on a $\mathrm{VN}$ nanowire array under ambient conditions. Chem. Commun. 54, 5323. doi:10. 1039/c8cc00459e

Zhang, Y., Qiu, W., Ma, Y., Luo, Y., Tian, Z., Cui, G., et al. (2018). Highperformance electrohydrogenation of $\mathrm{N}_{2}$ to $\mathrm{NH}_{3}$ catalyzed by multishelled hollow $\mathrm{Cr}_{2} \mathrm{O}_{3}$ microspheres under ambient conditions. ACS Catal. 8, 8540. doi:10.1021/acscatal.8b02311

Zhu, D., Zhang, L. H., Ruther, R. E., and Hamers, R. J. (2013). Photo-illuminated diamond as a solid-state source of solvated electrons in water for nitrogen reduction. Nat. Mater. 12, 836. doi:10.1038/nmat3696

Conflict of Interest: The authors declare that the research was conducted in the absence of any commercial or financial relationships that could be constructed as a potential conflict of interest.

The handling editor declared a past co-authorship with one of the authors JZ.

Copyright (C) 2020 Wang, Song, Liu and Zhang. This is an open-access article distributed under the terms of the Creative Commons Attribution License (CC BY). The use, distribution or reproduction in other forums is permitted, provided the original author(s) and the copyright owner(s) are credited and that the original publication in this journal is cited, in accordance with accepted academic practice. No use, distribution or reproduction is permitted which does not comply with these terms. 